\title{
A Study on the Modification of Composite Ceramic Tool
}

\author{
Haifeng Lu \\ Art Institute of Suzhou University School of Arts, Huzhou Teachers College, China
}

\begin{abstract}
Ceramic tool because of its high hardness characteristics are widely used in various types of cutting. Its fracture failure often occurs, so the poor toughness of ceramic materials is the main factor limiting the development. In order to overcome these disadvantages of poor toughness of ceramic cutting tools, the carbon nano tube as relatively excellent mechanical properties added into the $\mathrm{Al}_{2} \mathrm{O}_{3}$ matrix ceramic tool, and studies its performance optimization. Analyzed the different carbon nanotube content of $\mathrm{Al}_{2} \mathrm{O}_{3}$ ceramic cutting tool performance, $2 \%$ samples of carbon containing nano tube has the best mechanical properties.
\end{abstract}

KEYWORD: $\mathrm{Al}_{2} \mathrm{O}_{3}$ ceramic tool, Carbon nanotube, Modified

\section{BACKGROUND}

The grinding process pursuits the high efficiency and low cost in the future. High speed machining is the representative of the direction. At present, to meet the modern advanced manufacturing technology, low cost and environmental protection tool concept, it is ceramic tool (Yuan Shuai et al, 2015). Due to the characteristics of ceramic with high hardness and high brittleness, it is very prone to failure. Carbon nanotubes due to its high elastic modulus, high strength and good mechanical properties are widely used in the field of reinforced composites (Wu Zhenjiang et al, 2014) (Lu Changyong, 2013). This paper will be applied to the study of carbon nanotubes modified alumina-matrix composite ceramic tool. It hopes can make the mechanical properties of alumina-matrix ceramic tools are improved. It can make better use of the various types of cutting.

\section{EXPERIMENTAL MATERIALS AND EXPERIMENTAL PROCEDURES}

Table 1 Experimental material

\begin{tabular}{llll}
\hline $\begin{array}{l}\text { Material } \\
\text { name }\end{array}$ & purity & granularity & effect of raw material \\
\hline $\mathrm{Al}_{2} \mathrm{O}_{3}$ & $>99.9 \%$ & $<3 \mathrm{um}$ and & reinforcement and matrix \\
& & $30 \mathrm{~nm}$ & \\
$\mathrm{TiC}$ & $>99.9 \%$ & $<3 \mathrm{um}$ & reinforced phase \\
$\mathrm{Mo}$ & $>99.9 \%$ & $30-50 \mathrm{~nm}$ & binder \\
$\mathrm{Ni}$ & $>99.9 \%$ & $20-100 \mathrm{~nm}$ & binder \\
nanotube & $>99.9 \%$ & & additive \\
\hline
\end{tabular}

This experiment was prepared $\mathrm{Al}_{2} \mathrm{O}_{3}$ ceramic knife samples by hot pressing sintering. The main raw materials expect used nano $\mathrm{Al}_{2} \mathrm{O}_{3}$ powder and nano carbon tube, it is also used the additive, metal binder etc in the process of preparation $\mathrm{Al}_{2} \mathrm{O}_{3}$ ceramic tool. The raw materials are shown in Table 1.

After a lot of literature review (Jin Hua et al, 2013), preliminary determine the ratio of raw materials for preparation of $\mathrm{Al}_{2} \mathrm{O}_{3}$ ceramic tool as shown in Table 2.

Table 2 preparation of $\mathrm{Al}_{2} \mathrm{O}_{3}$ ceramic tool

\begin{tabular}{ll}
\hline raw material & Content $/ \mathrm{wt} \%$ \\
\hline $\mathrm{Al}_{2} \mathrm{O}_{3}$ powder & 5 \\
$\mathrm{TiC}$ & 25 \\
$\mathrm{Mo}$ & 7 \\
$\mathrm{Ni}$ & 3 \\
nanotube & $0-5$ \\
\hline
\end{tabular}

According to the melting point of raw materials and sintering conditions considering the phase transition temperature of $\mathrm{Al}_{2} \mathrm{O}_{3}$ matrix ceramic tool were determined (Duan Liuyang et al, 2015). The specific parameters are shown in Table 3.

Table 3 Sintering conditions Al2O3 ceramic knife

\begin{tabular}{cccc}
\hline $\begin{array}{c}\text { Sintering } \\
\text { parameters }\end{array}$ & $\begin{array}{c}\text { sintering } \\
\text { temperature }\end{array}$ & holding time & $\begin{array}{c}\text { sintering } \\
\text { stress }\end{array}$ \\
\hline $\begin{array}{c}\text { parameter } \\
\text { values }\end{array}$ & $1600^{\circ} \mathrm{C}$ & $30 \mathrm{~min}$ & $30 \mathrm{Mpa}$ \\
\hline
\end{tabular}

Preparation of $\mathrm{Al}_{2} \mathrm{O}_{3}$ composite ceramic tool material sample process as shown in Figure 1: 


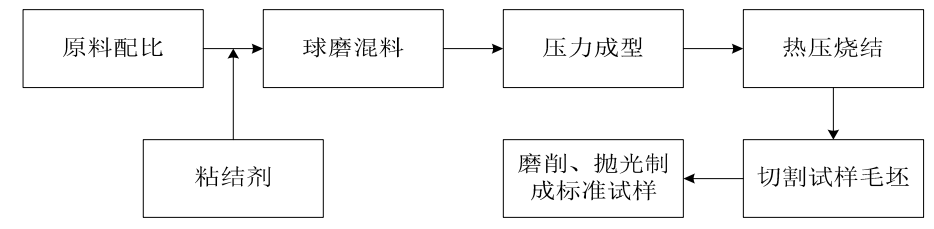

Figure 1 the sample process of materials $\mathrm{Al}_{2} \mathrm{O}_{3}$ composite ceramic tool

\section{THE RESULTS OF CHARACTERIZATION METHODS}

The mechanical properties of ceramic tool are the most important performance indexes. So this experiment tests the standard sample mechanical properties as following measurements.

\subsection{The anti-bending strength test}

According to the testing method of GB/T4741-1999 ceramic material anti-bending strength, it tested the anti-bending strength of SiC sintered ceramic samples. The anti-bending strength measurement of three samples, the result is average value. The principle is shown in Figure 2.
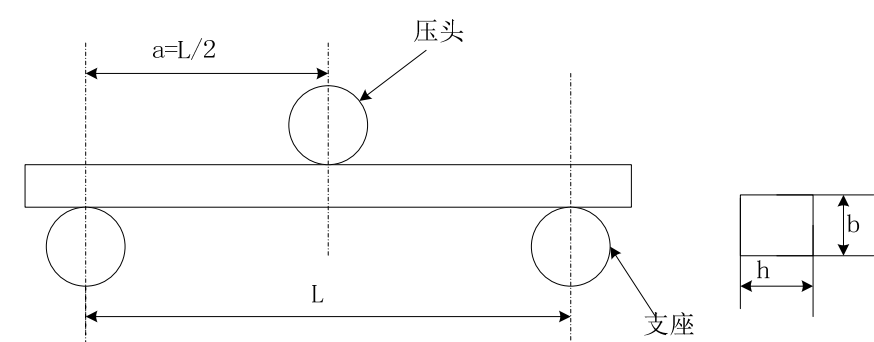

Figure 2 the anti-bending strength test principle diagram

The anti-bending strength calculation formula is as follow:

$$
\sigma_{b}=\frac{3 P L}{2 b h^{2}}
$$

In this formula: $\sigma$-three-point bending strength (Mpa)

P-the maximum load of fracture $(\mathrm{N})$

L-span (mm)

b-specimen width (mm)

h-specimen height $(\mathrm{mm})$

\subsection{Vickers hardness}

According to national standard GB16534-I996 indentation hardness tests Vivtorinox, it measured the indentation diagonal and the crack length by using optical microscope. Samples is 6 indentation measuring results averaged. Formula Vivtorinox hardness by indentation method is as follow:
$H_{V}=\frac{1.8544 P}{(2 a)^{2}}$

In this formula: Hv-Vickers hardness (Mpa);

P-indentation load (chosen 196N);

2a-the length of the diagonal of indentation ( $\mathrm{mm}$ ).

\subsection{Fracture toughness test}

Fracture toughness evaluation of ceramic materials used indentation method. Calculation of fracture toughness specimens from 6 indentation results averaged.

Figure 3 is a schematic diagram of indentation and crack.

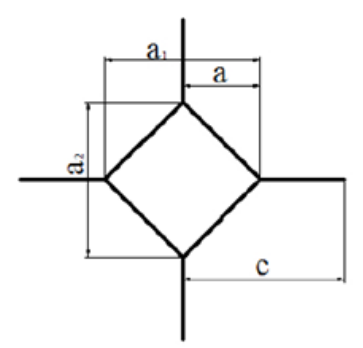

Figure 3 Schematic diagrams of indentation and crack.

It measured the indentation diagonal and the crack length by using optical microscope. The fracture toughness calculation formula of the indentation method is as follow:

$K_{I C}=0.37644 \times\left(\frac{c}{a}\right)^{\frac{3}{2}} \times \sqrt{a} \times \frac{P}{(2 a)^{2}} \times 10^{-6}$

In this formula: KIC-fracture toughness $\left(\mathrm{MPa} \cdot \mathrm{m}^{\frac{1}{2}}\right)$;

P-pressure load $(\mathrm{N})$;

a-the average value of the half length diagonal (m);

c-half length of crack (m).

\subsection{Fracture morphology}

In this experiment, the morphology of the material fracture observed by scanning electron microscopy (SEM).

\section{RESULTS AND ANALYSIS}

The main purpose of this experiment is analyzed the content of $\mathrm{Al}_{2} \mathrm{O}_{3}$ ceramic tool materials carbon nanotubes and the variation material performance and influence. According to the difference content of carbon nanotubes in the raw materials, it tabbed the different sample. The relationship between sample 
label and the content of carbon nanotubes are shown in Table 4.

Table 4 the corresponding relationship between the number and content of carbon nanotubes samples

\begin{tabular}{|c|c|c|c|c|c|c|}
\hline Sample number & $\mathrm{T}_{0}$ & $\mathrm{~T}_{1}$ & $\mathrm{~T}_{2}$ & $\mathrm{~T}_{3}$ & $\mathrm{~T}_{4}$ & $\mathrm{~T}_{5}$ \\
\hline $\begin{array}{c}\text { Content of carbon } \\
\text { nanotubes/wt } \%\end{array}$ & 0 & 1 & 2 & 3 & 4 & 5 \\
\hline
\end{tabular}

\subsection{Carbon nanotube content affected on anti- bending strength of $\mathrm{Al}_{2} \mathrm{O}_{3}$ ceramic cutting tool}

The $\mathrm{Al}_{2} \mathrm{O}_{3}$ ceramic tools anti-bending strength of different carbon nanotubes content is shown in Figure 4.

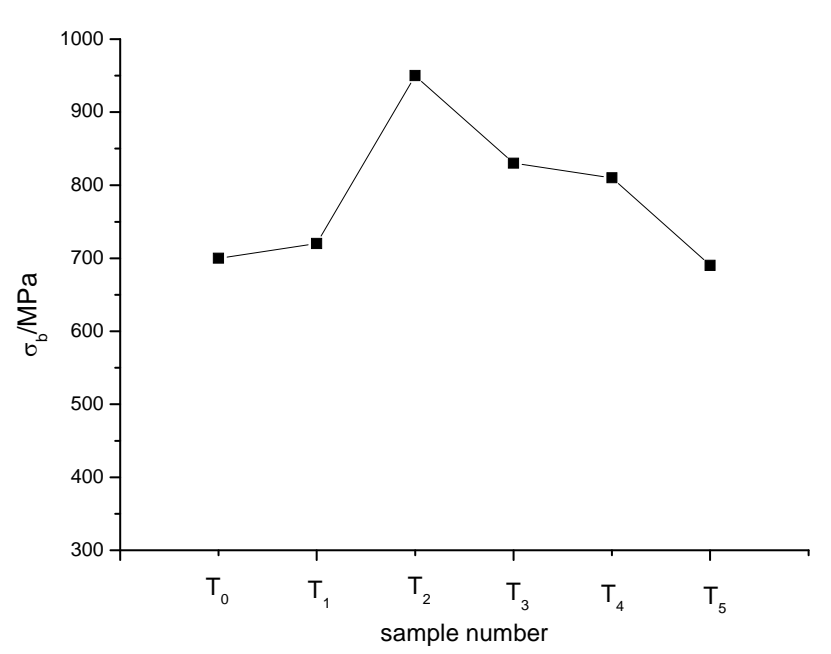

Figure 4 Carbon nanotube content affected on anti-bending strength of $\mathrm{Al} 2 \mathrm{O} 3$ ceramic cutting tool

For the $\mathrm{Al}_{2} \mathrm{O}_{3}$ composite ceramics, the carbon nano tube after adding different content. The antibending strength of $\mathrm{Al}_{2} \mathrm{O}_{3}$ composite ceramic material has increased and then decreased with the contents of nanotube increasing. But the anti-bending strength of T2 sample (the content of nanotube is $2 \%$ ) up to $935 \mathrm{MPa}$. We can have the conclusion: When the carbon nanotubes $/ \mathrm{Al}_{2} \mathrm{O}_{3}$ composite ceramic material density is very high, the internal defect is less, such as pores, micro cracks etc. Then the carbon nanotubes $/ \mathrm{Al}_{2} \mathrm{O}_{3}$ composite ceramic material has stronger anti-bending strength. We can also find that many of the nanoparticles did not increase the anti-bending strength of carbon nano tube $/ \mathrm{Al}_{2} \mathrm{O}_{3}$ composite ceramic material. It will reduce the antibending strength of the material. In summary, the added content of carbon nanotubes should be between $1-3 \%$. It can make the composite ceramic tool material which has a high anti-bending strength.

\subsection{Content of carbon nanotubes effected on $\mathrm{Al}_{2} \mathrm{O}_{3}$ ceramic tool Vivtorinox hardness}

The difference carbon nanotubes content antibending strength of $\mathrm{Al}_{2} \mathrm{O}_{3}$ ceramic cutters is shown in Figure 5.

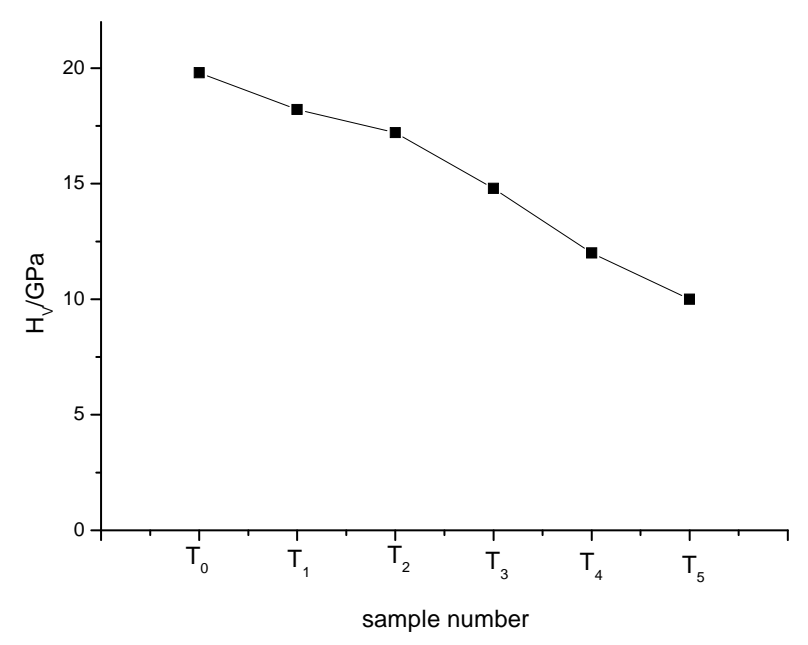

Figure 5 Content of carbon nanotubes affected on $\mathrm{A} 12 \mathrm{O} 3$ ceramic tool Vivtorinox hardness

Vivtorinox hardness measurement of $\mathrm{Al}_{2} \mathrm{O}_{3}$ composite ceramic material values also appeared to decline. Integrated some research shows that its particle size smaller more easily sintered in the process of sintering preparation. At the same time particles also tend to be the reunion. The rapid growth of agglomeration easily, it caused grain defects. So it added too much carbon nano tube, it will often make a large number of carbon nanotubes together. It is bad for the densification. The prepared materials tend to present many holes. The diamond indenter pressured to the hole will be increased tested by the Vivtorinox hardness. The measured hardness values will reduce.

\subsection{Carbon nanotube content affected on fracture toughness of $\mathrm{Al}_{2} \mathrm{O}_{3}$ ceramic tool}

The difference content of carbon nanotubes $\mathrm{Al}_{2} \mathrm{O}_{3}$ ceramic tool's fracture toughness are shown in Figure 6.

Fracture toughness measurement of carbon nanotubes $/ \mathrm{Al}_{2} \mathrm{O}_{3}$ composite ceramic material values also appeared increased and then decreased. When it added carbon nano tube content is $1-2 \%$, it can be fracture of $\mathrm{Al}_{2} \mathrm{O}_{3}$ composite ceramic tool toughness roughly doubled. But when the carbon nano tube added the content gradually increased, the fracture toughness exhibited to reduce. This research is applied in hot pressing sintering method. It is played a very good guarantee on the density of the composite, and plays a guarantee on the performance. Due to the toughening effect of carbon nanotubes, the $\mathrm{Al}_{2} \mathrm{O}_{3}$ composite ceramic tool materials show the strong 
fracture toughness. The fracture toughness of the composites increased significantly. However, the fracture toughness of materials $\mathrm{Al}_{2} \mathrm{O}_{3}$ composite ceramic cutting tool with the increase of carbon nanotube amount has been increasing. When the content of carbon nanotubes exceeds $4 \%$, the fracture toughness of composite materials did not get any improvement. There will be even larger matrix defects, such as, appearing hole etc. The comprehensive performance of new composite materials will be severely damaged. The fracture toughness will be lower.

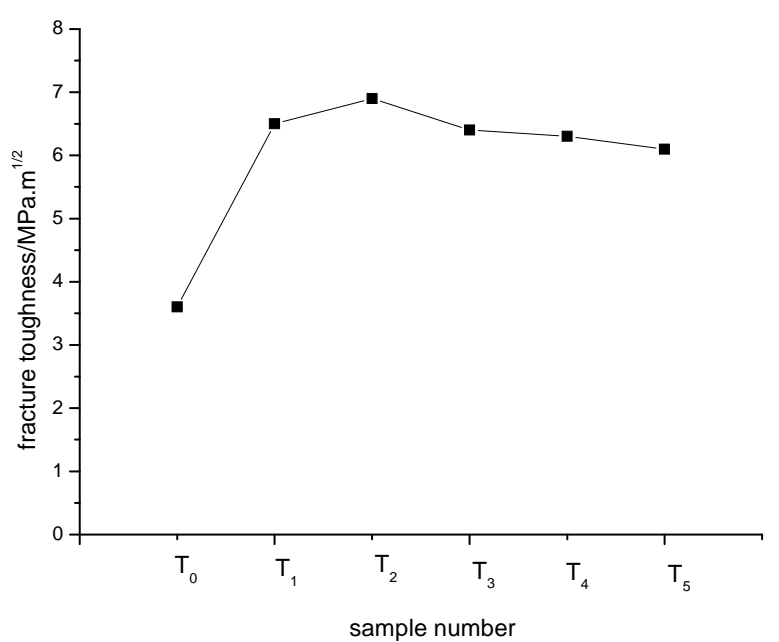

Figure 6 Carbon nanotube content affected on fracture toughness of $\mathrm{Al} 2 \mathrm{O} 3$ ceramic tool

\subsection{Carbon nanotube content affected on fracture morphology of $\mathrm{Al}_{2} \mathrm{O}_{3}$ matrix ceramic tool}

From the front of the three indexes analysis, cutter mechanics $\mathrm{Al}_{2} \mathrm{O}_{3}$ ceramics prepared with excellent performance with the carbon nanotube content in the range of $1-3 \%$. Then we special study the $\mathrm{Al}_{2} \mathrm{O}_{3}$ matrix ceramic tool fracture morphology (2000 times) which the content of carbon nanotubes was $0-3 \%$. As shown in Figure 7.
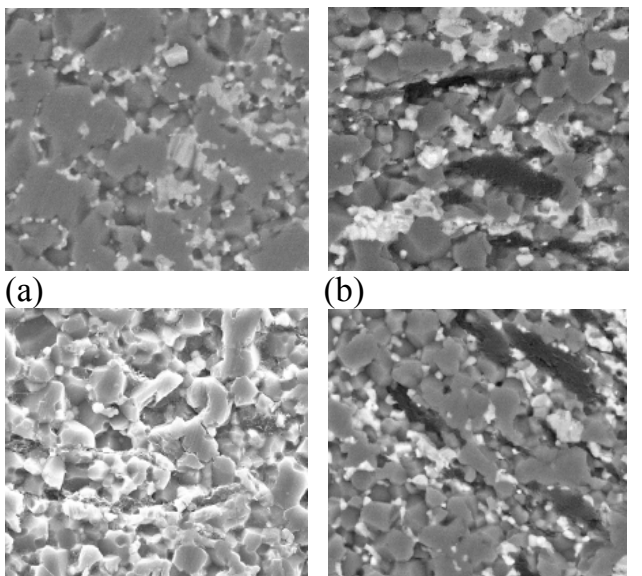

(b)

(c)

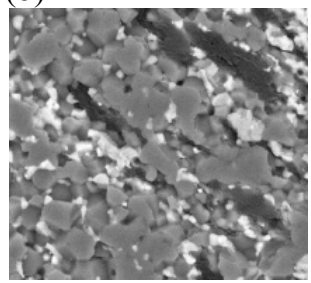

(d)
In Figure 7 (a), it is not difficult to find that between alumina particles which exhibit a very close combination without the addition of carbon nanotubes. Is there any basic pore, the density is very high. The dominant crack is mainly intergranular and transgranular fracture. In Figure 7(b), when the matrix add $1 \%$ carbon nanotubes, the combination between alumina particles which exhibit still very close. Only a small part of the pore, the density is higher. But there is a small amount of slender carbon nanotubes diameter to the original matrix interspersed. There are some short carbon nanotubes in peripheral section. In the figure 7(c), When the matrix added 2\% carbon nanotubes, the combination between alumina particles which exhibit still very close, and only a few pores. Compared with adding $1 \%$ carbon nanotubes, the more slender carbon nanotube diameter into the original matrix, and there are a lot of short carbon nanotube terminals in the section. In figure $7(\mathrm{~d})$, when the substrate added 3\% carbon nanotubes, the combination between the alumina particles which exhibit still close, and there are more pores. It also increased significantly in the section of carbon nanotube terminals.

\section{CONCLUSION}

Due to the high hardness and high brittleness of ceramic properties, ceramic tool in high speed machining is often broken. So this paper will test the excellent mechanical properties of modified carbon nano tube $\mathrm{Al}_{2} \mathrm{O}_{3}$ ceramic cutting tools. Analysis of mechanical properties and fracture morphology of the $\mathrm{Al}_{2} \mathrm{O}_{3}$ through the ceramic tool based on different content of carbon nanotubes, when adding carbon nano tube content is $2 \%$. The composite new material comprehensive performance is the best. Compared with $\mathrm{Al}_{2} \mathrm{O}_{3}$ materials without CNTs composite ceramic cutting tool, the anti-bending strength increased $33.95 \%$. The fracture toughness increased $92.98 \%$. A substantial increase in anti-bending strength and fracture toughness can effectively broaden the scope of application of ceramic tools, high speed cutting tool has better performance for more industry.

\section{ACKNOWLEDGMENTS}

This paper was supported by Ministry of education of humanities and social science research planning fund project funding: 14 YJA760019
Figure 7 (a) containing 0\% carbon nanotubes; (b) containing $1 \%$ carbon nanotubes; (c) containing $2 \%$ carbon nanotubes; (d) containing $3 \%$ carbon nanotubes 


\section{REFERENCES}

Duan Liuyang, Luo Lei, Wang Yiguang. The Modification and the Ablation Behavior of Ultra High Temperature Ceramic Matrix Composites.[J]. Materials China, 2015(10): 762-769.

Jin Hua, Meng Songhe, Xie Weihua,et al. Study on the Factors Affected the Performance of Ultra High Temperature Ceramic Composite Material Thermal Shock[J]. Journal of Solid Rocket Technology, 2013, 36(2): 255-260.

Lu Changyong. In Situ Synthesis of Carbon Nanotubes in the Ceramic Powder[D]. Wuhan University of Technology, 2013.

Wu Zhenjiang, Huang Xinmin, Yu guoliang and et al. Study on the Properties and Composite Materials and Nano Structure of Aluminum Carbon Tube[J]. Shanghai Nonferrous Metals, 2014(3): 93-99.

Yuan Shuai, Liu Xianli and Yue Caixu. The Application and Development of Ceramic Cutting Tools[J]. Metal Processing: Cold working, 2015(6): 57-59. 